\title{
A Singular Voltage Stability Indices Approach to Spot Out Weedy Bus Under Contingency Environment
}

\section{Dr.Jayachitra Selvaraj}

Department of Computer Engineering, College of Engineering and Computer Science, Lebanese French University, Erbil, Iraq jayachitraselvaraj@Ifu.edu.krd

\section{ARTICLE INFO}

\section{Article History:}

Received: 22/4/2020

Accepted: 4/9/2020

Published: Summer 2020

\section{Keywords:}

Compound Index; FACTS;

Synthesis Severity Index; voltage stability

Doi:

\section{ABSTRACT}

Voltage stability estimation is one of the foremost parameter in monitoring the power system stability. Various voltage stability indices had been developed by researcher for voltage stability assessment. These indices were executed for spotting the pathetic transmission lines/buses. Here forth the placement and sizing of FACTS devices to trigger countermeasures against voltage instability/blackouts. In this paper two voltage stability indices were proposed called Synthesis Severity Index (SSI) and Compound Index ( $\mathrm{Cl}$ ).These indices had been implemented on IEEE 14 and 30 bus system under generator and line contingencies. The resulted were presented and discussed.

10.25212/Ifu.qzj.5.3.38

\section{INTRODUCTION}

In the modern years, power systems are committed to operate under stressed condition owing to the continuous magnification of power demand and limited scope of expanding the existing system network. Reactive power cannot be transmitted over a long distances.[1] If the load demands reactive power, then it 
has to be delivered directly to the point, which requisite reactive power support. At this situation, if the system voltage drops and any sudden disturbance occurred (for example, line outage; generation loss; or any fault), then eventually system would be triggered to fall under the voltage instability region. Sometimes it may end up to voltage collapse. The primary factor of causing voltage instability is, when system fails to give up reactive power which is demanded by the load under heavily stressed condition [2].

The voltage collapse/block out is a development by which voltage instability leads to drop in voltage magnitude in a significant part of the power system. In general, this phenomenon might be happened due to failure of the equipments/controllers, outages of branches or a great difference between the forecasted and actually consumed power [3].

The Other factors contributing the voltage stability are the generator reactive power limits, nature of the load, characteristics of reactive compensation regulators and the action of voltage control devices [4].

In voltage stability analysis, real power and reactive power capabilities of the generator participate a significant mission. The active power boundaries are set by the design of the turbine and boiler. Therefore, real power limits of the generators are invariable. However, factors which fixing the reactive power limits of generators are stator current, over-excitation current and under-excitation limits. Hence VAR limit of the generator is more convoluted than active power limits. The generator's field current is controlled by over-excitation limiter to avoid damage of the field winding $[5,6]$. In power flow analysis program, reactive power limits are taken to be constant just for simplification.

The potential of this research paper is to propose new voltage indices to identify weedy buses and transmission lines. Section 2 discussed about the theory of voltage stability indices and their formulation. Section 3 goes with formulation of new indices. In section IV the detailed results and discussion with 2 cases called IEEE 14 and 30 bus systems. Finally the article ends up with conclusions. 


\section{INDEX ANALYSIS}

The voltage stability indices are invaluable tools, which appraise the state of voltage stability in a power system under the regular and abnormal conditions. These indices may be based on either static analysis or dynamic models of the power systems. The index estimates an arithmetical value to each load bus. If the index value is moving towards zero, then the system is postulated as stable and also improves system security. When the index value moves away from zero, the stability of system is relatively decreases then the system is theorized as unstable [7].

\section{A. Voltage Stability Indices}

The Voltage Stability Indices stated below are derived with respect to two bus system model for simplicity and had been realized in the actual system. The single line diagram of a two bus system model is shown in Figure 1.

The following hypotheses are taken into account before proceeding to derivation part.

- Lossless transmission line

- Bus voltage magnitude at sending and receiving end remains constant.

- Maximum power transfer is evaluated at load angle $\delta=90^{\circ}$

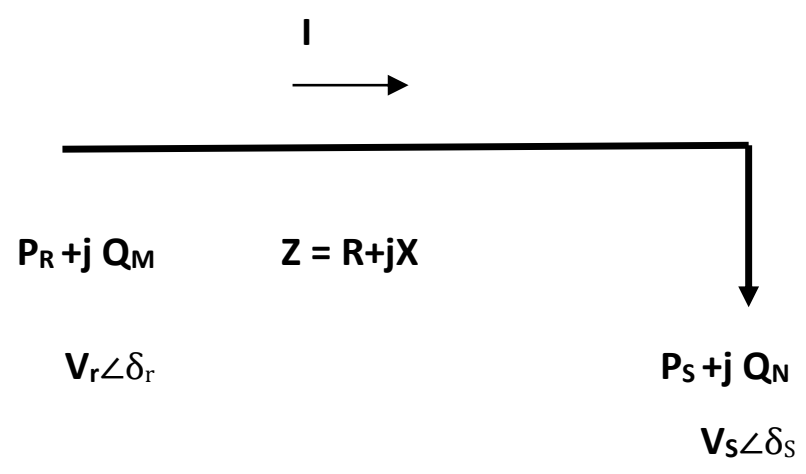

Figure 1 Single line diagram of a two bus system 


\section{QALAAI ZANISTSCIENTIFIC JOURNAL \\ A Scientific Quarterly Refereed Journal Issued by Lebanese French University - Erbil, Kurdistan, Iraq \\ Vol. (5), No (3), Summer 2020 \\ ISSN 2518-6566 (Online) - ISSN 2518-6558 (Print)}

\section{FORMATION OF INDEX}

The most severe line ranking and henceforth placement of FACTS devices had been accomplished on the basis of Synthesis Severity Index (SSI). This SSI is framed according to the weighted aggregate of Contingency Severity Index (CSI) and Fast Voltage Stability Index (FVSI). The CSI is especially deputed for the assessment of line overloads in terms of both real and reactive power and FVSI had been chosen for voltage stability appraisal. However, SSI is composed as a mixture of CSI and FVSI. Similarly, the most severe line grading is carried out through a new concept called Compound Index (CI). It is the blend of CSI and VCPI.

\section{A. Contingency Severity Index (CSI) [8-12]}

Stage 1: Find the participation matrix. $-U_{r s}$ matrixlt is used to diagnose the branches which are overloaded. The matrix value is either one or zero. If the power flow through a line is above it's thermal limit, $U_{r s}$ matrix value is concluded as one otherwise zero.

Stage 2: Find the ratio matrix. $-\mathrm{W}_{\mathrm{rs}}$ matrix

It is value is determined by the power flow through a line during contingency period.

$\mathrm{W}_{\mathrm{rs}}=\left(\frac{\mathrm{P}_{\mathrm{r}(\text { conti) }}}{\mathrm{P}_{\mathrm{r}(\text { base })}}\right)-1$

Stage 3: Find the contingency probability array $\left(P_{r}\right)$.

This array is used to describe the probability of branch outages. In this research study, it is postulated as 0.02 in case, the power flow through branch exceeds its thermal limit.

Stage 4: Enumerate CSI for all the branches in the network.

The contingency severity index (CSI) for branch $b$ is defined as the sum of sensitive at node $\mathrm{s}$ to all considered $\mathrm{N}-1$ contingencies and it is expressed as 


$$
\text { Contingency Severity Index } \mathrm{CSI}_{\mathrm{s}}=\sum_{r=1}^{\mathrm{x}}\left(\mathrm{P}_{\mathrm{r}} \mathrm{U}_{\mathrm{rs}} \mathrm{W}_{\mathrm{rs}}\right)
$$

\section{B. Synthesis Severity Index (SSI)}

The CSI had contributed to estimate transmission line overloading. FVSI indicates the voltage stability of the system. Both indices had been united to frame SSI, which is used to retrieve an overall stress estimation of the line.

After obtaining the CSI and FVSI values of all the lines for a distinct line outage, the SSI is enumerated as given in Equation(3).

$\mathrm{SSI}_{\mathrm{rs}}=\mathrm{P}_{1} * \mathrm{CSI}_{\mathrm{rs}}+\mathrm{P}_{2} * \mathrm{FVSI}_{\mathrm{rs}}$

\section{RESULT AND DISCUSSIONS}

Case Study 1: 14 bus system

An IEEE 14 bus system has totally five generator buses (bus 1 is termed as slack bus 2, 3, 6 and 8 are PV buses) fourteen PQ buses and twenty transmission lines. Among these, three transmission lines (4-7), (4-9) and (5-6) are with tap changing transformers. Each of the four generator buses had been isolated from the network sequentially for the purpose of contingency analysis. Using N-R power flow method, the performance of the generator outage had been indexed in Table 1. It was noticed that, for instance, termination of generator bus number 2 , the branch 2-3 had the peak $\mathrm{Cl}$ value, was the severe-most line of the system

\section{Table 1 Generator Contingency analysis on IEEE 14 bus network}

\begin{tabular}{|c|c|c|}
\hline S.No & $\begin{array}{l}\text { Generator bus } \\
\text { Number }\end{array}$ & $\sum$ of $\mathbf{C l}$ \\
\hline 1 & 2 & 0.554 \\
\hline 2 & 6 & 0.552 \\
\hline 3 & 8 & 0.549 \\
\hline
\end{tabular}

To analyse the network under stressed conditions, contingency analysis was accomplished by simulating single line outage to distinguish the critical 


\section{QALAAI ZANISTSCIENTIFIC JOURNAL \\ A Scientific Quarterly Refereed Journal Issued by Lebanese French University - Erbil, Kurdistan, Iraq \\ Vol. (5), No (3), Summer 2020 \\ ISSN 2518-6566 (Online) - ISSN 2518-6558 (Print)}

contingencies. According to this, totally twenty $(\mathrm{N}-1)$ single line contingencies are possible. For each contingency, Synthesis Severity Index (SSI) values are enumerated. The branches with high index of SSI are identified as critical lines, which VAR needed support. The ranking of the branches were done in connection with SSI. The most severe lines are graded in Table 2. From that Table, the most severe contingencies are acknowledged as (1-2), (5-6), (1-5) and (2-3).

Table 2 Selected severe congested lines in IEEE 14 Bus system using SSI

\begin{tabular}{|l|l|l|l|l|}
\hline \multirow{2}{*}{ S.No } & \multicolumn{2}{|l|}{$\mathbf{( N - 1 ) \text { contingency }}$} & \multirow{2}{*}{ SSI } & $\begin{array}{l}\text { Overall } \\
\text { rank }\end{array}$ \\
\cline { 2 - 3 } & Starting bus & $\begin{array}{l}\text { Ending } \\
\text { bus }\end{array}$ & & \\
\hline 1 & 5 & 6 & 0.0626 & 1 \\
\hline 2 & 1 & 2 & 0.0461 & 2 \\
\hline 3 & 1 & 5 & 0.0423 & 3 \\
\hline 4 & 2 & 3 & 0.0295 & 4 \\
\hline
\end{tabular}

Case Study 2: IEEE 30 bus system

An IEEE 30 bus system has totally 5 generator buses namely 2, 5, 8, 11 \& 13 and 41 transmission lines. Each of the 5 generator buses had been isolated from the network sequentially for the purpose of contingency analysis. Using N-R power flow method, the performance of the generator outage had been indexed in Table 3. It was noticed that, for instance, removal of generator bus number 11, the branch 2-5 had the zenith $\mathrm{Cl}$ value, was the severe-most line of the 30 bus system.

Table 3 Generator Contingency analysis on IEEE 30 bus network

\begin{tabular}{|c|c|c|}
\hline S.No. & $\begin{array}{c}\text { Generator bus } \\
\text { Number }\end{array}$ & $\sum$ of Cl \\
\hline 1 & 2 & 0.264 \\
\hline 2 & 5 & 0.263 \\
\hline 3 & 8 & 0.260 \\
\hline 4 & 11 & 0.261 \\
\hline 5 & 13 & 0.2603 \\
\hline
\end{tabular}

To analyse the network under stressed conditions, contingency analysis was accomplished by simulating single line outage to distinguish the critical 


\section{QALAAI ZANISTSCIENTIFIC JOURNAL \\ A Scientific Quarterly Refereed Journal Issued by Lebanese French University - Erbil, Kurdistan, Iraq \\ Vol. (5), No (3), Summer 2020 \\ ISSN 2518-6566 (Online) - ISSN 2518-6558 (Print)}

contingencies. According to this, totally $41 \mathrm{~N}-1$ contingencies are possible but N-R power flow converges for 37 line outages out of 41 line outages. For each contingency, Synthesis Severity Index (SSI) values are enumerated. The branches with high index of SSI are identified as critical lines, which needs VAR support. The ranking of the branches are done in connection with SSI. The most severe lines are graded in Table 4. From that table, the most severe contingencies are acknowledged as (1-2), (4-6), (2-5) and (1-3).

Table 4 Selected severe congested lines in IEEE 30 Bus system using SSI

\begin{tabular}{|c|c|c|c|c|}
\hline \multirow{2}{*}{ S.No } & \multicolumn{2}{|c|}{ (N-1)contingency } & \multirow{2}{*}{} & \multicolumn{2}{l|}{$\begin{array}{l}\text { Overall } \\
\text { rank }\end{array}$} \\
\cline { 2 - 3 } & $\begin{array}{c}\text { Starting } \\
\text { bus }\end{array}$ & $\begin{array}{c}\text { Ending } \\
\text { bus }\end{array}$ & SSI & 1 \\
\hline 1 & 1 & 2 & 0.1175 & 2 \\
\hline 2 & 4 & 6 & 0.1151 & 3 \\
\hline 3 & 2 & 5 & 0.0884 & 4 \\
\hline 4 & 1 & 3 & 0.0416 & \\
\hline
\end{tabular}

\section{CONCLUSION}

The importance of voltage stability indices were presented. The formulation of Synthesis Severity Index and Compound index had been revealed. These indices were implemented under generator as well as transmission line contingencies. The weedy buses and transmission lines were discussed and presented. These novel approaches are easy to implement to figure out the assessment of voltage stability.

\section{REFERENCES:}

[1]Siddiqui A. and Tanmoy Deb (2014), 'Improved gravitational search algorithm for loadability enhancement of transmission lines using UPFC', International Journal of System Assurance Engineering and Management, Vol 5(3), pp 444-449.

[2].Preethi, V. A., S. Muralidharan, and S. Rajasekar. "Application of genetic algorithm to power system voltage stability enhancement using facts devices." Recent Advancements in Electrical, Electronics and Control Engineering (ICONRAEeCE), 2011 International Conference on. IEEE, 2011. 


\section{QALAAI ZANISTSCIENTIFIC JOURNAL \\ A Scientific Quarterly Refereed Journal Issued by Lebanese French University - Erbil, Kurdistan, Iraq \\ Vol. (5), No (3), Summer 2020 \\ ISSN 2518-6566 (Online) - ISSN 2518-6558 (Print)}

[3].Gitizadeh, M., and M. Kalantar. "A new approach for congestion management via optimal location of FACTS devices in deregulated power systems." Electric Utility Deregulation and Restructuring and Power Technologies, 2008. DRPT 2008. Third International Conference on. IEEE, 2008.

[4]S.Jayachitra and G.Baskar (2018), “Application of mutation inspired constrained factor PSO considering voltage stability and losses by locating and rating TCSC during N-1 contingency", International Journal of Reasoning based Intelligent system, Vol. 10, Nos. 3/4, 2018, pp 174-182

[5]Kianersi H. and Hamid A. (2015), 'Voltage Stability Improvement By Using FACTS Elements With Economic Consideration', Ciencia e Natura, pp 162-167.

[6] Malathy P. and Shunmugalatha A. (2016), 'Loadability analysis during single contingency with FACTS devices using Differential Evolution', Proceedings of 2016 IEEE 6th International Conference on Power Systems (ICPS), pp 1-6.

[7]Sutha S. and Kamaraj N. (2008), 'Optimal location of multi type facts devices for multiple contingencies using particle swarm optimization', International Journal of Electrical and Computer, Vol.2(10) pp 2275-2281

[8]Dahej A., Esmaeili S. and Goroohi A. (2012), 'Optimal allocation of SVC and TCSC for improving voltage stability and reducing power system losses using hybrid binary genetic algorithm and particle swarm optimization', Canadian Journal on Electrical and Electronics Engineering, Vol 3(3), pp 100-107

[9] Jayachitra S (2018), "Bio Inspired Mutation based CFPSO to Optimize Size and Location of FACTS Device Under Generator Contingency", Eurasian Journal of Analytical Chemistry, Vol.13 No. 6b(2018), pp 23-37.

[10] Balamurali G. and Thanushkodi K. (2011), 'Novel selection factors based optimal placement of TCSC controller in power transmission system for contingencies using PSO', Proceeding in IET International Conference on Sustainable Energy and Intelligent Systems (SEISCON 2011), PP. $352-357$

[11]Balamurali.G, "Optimal Placement of TCSC \& UPFC Controllers In Grid System Using Multiple Indices”, Ph.d thesis,2015.

[12]. S.Jayachitra and G.Baskar (2018), "Application of mutation inspired constrained factor PSO considering voltage stability and losses by locating and rating TCSC during N1 contingency", International Journal of Reasoning based Intelligent system, Vol. 10, Nos. 3/4, 2018, pp 174-182 


\section{QALAAI ZANISTSCIENTIFIC JOURNAL}

A Scientific Quarterly Refereed Journal Issued by Lebanese French University - Erbil, Kurdistan, Iraq

Vol. (5), No (3), Summer 2020

ISSN 2518-6566 (Online) - ISSN 2518-6558 (Print)

الملخص

يعد تقدير إستقرار الجهـ أحد أهم العوامل في مراقبة استقرار نظام الطاقة. تم تطوير العديد من مؤشرات

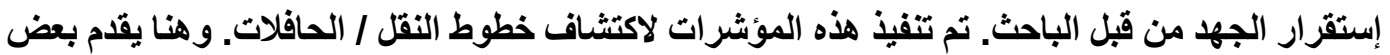

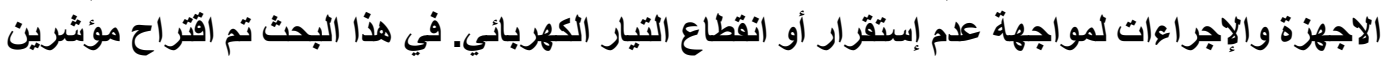

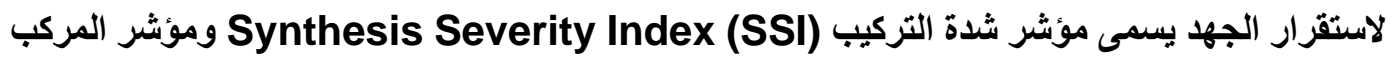
جأ Compound Index تحت طوارئ المولدة والخط. ومن ثم تم عرض النتائج ومناقشتها.

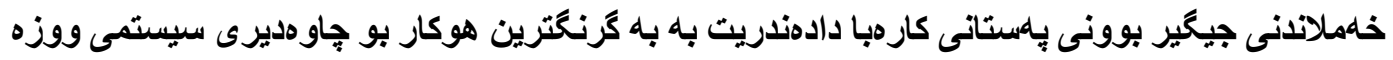

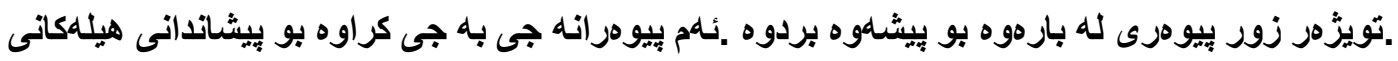

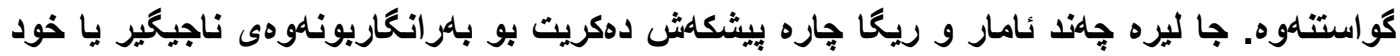

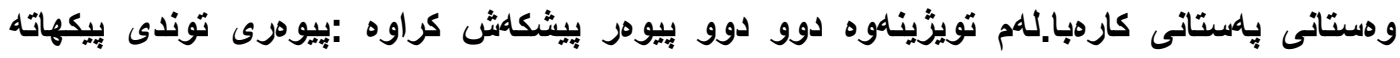

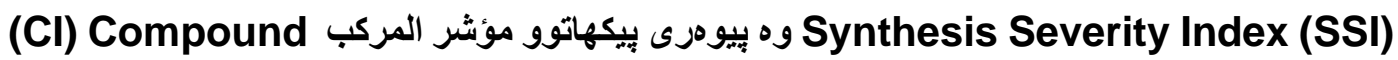

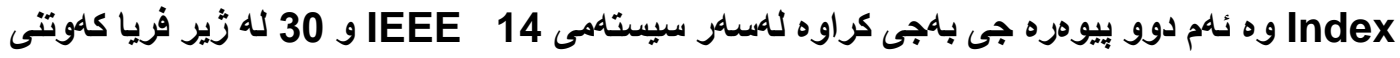

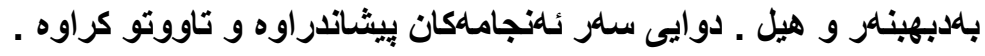

